https://doi.org/10.15407/ujpe65.4.327

I.P. ILCHYSHYN, E.A. TIKHONOV

Institute of Physics, Nat. Acad. of Sci. of Ukraine

(46, Nauky Ave., Kyiv 03028, Ukraine; e-mail: ilchyshynigor@gmail.com)

\title{
HOW LASER PHYSICS BROUGHT OPTICS TO THE WORLD OF PHOTONIC CRYSTALS ${ }^{1}$
}

\begin{abstract}
A brief review of authors' research is presented. An emphasis is made on the photon localization in the helical structure of a chiral liquid crystal $(C L C)$, which was first experimentally registered by the authors. An analysis of the spectral and lasing characteristics of distributed feedback (DF) lasers based on natural CLCs (type 1) and on chiral nematics (type 2) led to a conclusion that the model of photonic crystal is suitable to describe the lasing mechanism in type-2 CLC lasers, but not in type-1 ones. This conclusion is evidenced by the absence of lasing bands at the opposite edges of the selective reflection (SR) band; at the same time, the lasing line is located at its center. It is shown that if the $S R$ band of the CLC overlaps the maximum of the laser dye fluorescence band, the lasing line coincides with the SR band center to an error of $\pm 1 \mathrm{~nm}$. If the layer thickness in the CLC lasers of both types does not exceed $50 \mu \mathrm{m}$, when a high-quality planar texture is retained and a low generation threshold is achieved, a significant difference between their optical characteristics takes place. Namely, the SR spectrum for a type-1 CLC laser is approximately described by a Lorentzian profile, whereas the contour of the SR spectrum for a type-2 CLC laser has a profile characteristic of the transmittance through multilayer dielectric mirrors. The origins of the differences between the optical and laser characteristics of the CLC lasers of both types have been analyzed from the viewpoint of two lasing models: DF and photonic-crystal ones.
\end{abstract}

Keywords: chiral liquid crystal, planar texture, photonic crystal, transmission spectrum, fluorescence, lasing spectrum.

\section{Introduction}

The study of the spontaneous radiation emission in the case where a periodic structure has a period comparable with the light wavelength in the optical spectral interval has been a matter of interest to physicists for a long time, but it was constrained by the complexity of the relevant experimental verification. In 1972, Bykov [1] theoretically considered the conditions required for an atom to emit in a periodic structure. The cited author found a significant lifetime increase for the atomic radiation emission with frequencies falling within the band gap of the periodic structure. In 1974, Dreher and Schomburg [2] experimentally studied the fluorescence of impurity molecules embedded into a natural periodic chiral liquid crystal (CLC) structure, with the fluorescence being registered along the helix axis. The cited experiments confirmed the theoretical prediction made in work [1] about an increase of the fluorescence emission time for

(c) I.P. ILCHYSHYN, E.A. TIKHONOV, 2020

ISSN 2071-0194. Ukr. J. Phys. 2020. Vol. 65, No. 4 frequencies lying within the band gap. The authors of work [2] determined the growth of the radiation emission time for various fluorescence lines of tetraphene molecules in CLCs: from $6 \%$ at $\lambda=386 \mathrm{~nm}$ to $66 \%$ at $\lambda=410 \mathrm{~nm}$.

The concept of photonic crystal was included into the literature by Yablonovitch [3], who predicted conditions for such a crystal to exist; namely, the fluorescence quenching within the band gap limits of the periodic structure and the photon localization in this structure. It was emphasized that a necessary condition for the photonic crystal existence is a sufficiently large modulation depth of the basic parameter of the periodic structure.

It should be noted that the phenomenon of photon localization in the periodic CLC structure manifests itself as the fluorescence quenching in the helix axis

1 The paper was presented at XXIVth Galyna Puchkovska International School-Seminar "Spectroscopy of Molecules and Crystals" (August 25-30, 2019, Odesa, Ukraine). 
direction at selective reflection (SR) frequencies. This phenomenon together with the effect of the laser generation in dye-doped CLCs was firstly registered in our works $[4,5]$. This discovery was made long before the work by Yablonovitch [3], as well as the experiment that he referred to [6], was published. The realization of lasing on the basis of a natural structured material-in particular, CLC [4]-made it possible to create a low-threshold microlaser with an active medium that possesses an arbitrary area and an arbitrary curvature. Such lasers are considered to be promising for the development of high-brightness displays capable of reproducing information under bright illumination conditions.

The CRC lasers as elements of novel bright displays continue to be studied at scientific centers. A number of significant results have been obtained using new CLC materials [7-9]. In particular, they concern the extension of the interval of generation frequency tuning [10], the methods of generation frequency tuning $[11,12]$, the ways to enhance the energy yield of a CLC laser [13-15], and the degradation dynamics of its active element [16].

In recent years, CLC lasers with defects in their helical structure, which leads to the appearance of defect modes in the forbidden gap, have been actively studied. The modern theory of laser generation in photonic CLCs predicts that providing the defects of certain types in the helical structure and depending on the ratio between the defect layer thickness and the total CLC thickness, one or a few "dips" may arise in the SR spectrum thus creating a condition for the excitation of lasing inside the SR band [17]. The results of modern studies of CLC lasers were reported in a number of reviews [18-22].

The understanding of the mechanism of laser generation in a helical CLC structure was firstly developed on the basis of the distributed feedback (DF) laser with either a linear periodic structure [23] or its modifications in the case of helical structure $[24,25]$. Later, the mechanism of CLC laser generation was supplemented by the model of photonic crystals $[18,26,27]$. According to this model, the generation thresholds in nematics with the induced helix (induced CLCs) are minimum at the forbidden gap (the SR band) edges, whereas the generation within the forbidden gap is possible only provided the presence of a defect in the helical structure. The study of CLC lasers based on cholesterol esters, which are character- ized by low birefringence and have a small modulation depth of the periodic helix structure, showed a good agreement with theoretical conclusions [23-25]. Namely, (i) the lasing spectrum is located at the center of the SR band, and its position does not change with the growing excitation intensity; (ii) according to the theory [25], a strong selection of longitudinal modes (no more than three) takes place; (iii) because of a relatively strong coupling between the waves propagating in opposite directions in such a structure [23], the energy efficiency of the laser decreases by almost an order of magnitude; and (iv) there is a strong dependence of the generation threshold on the active layer thickness.

After the appearance of the photonic-crystal model, the authors of some works [20,27] argued that it can be applied to describe the generation mechanism in the CLC lasers on the basis of a natural helical structure (lasers of type 1), whereas the observed generation at the SR band center is a result of the poor-quality defect planar texture [27], so that a doublet has to be observed in the lasing spectrum [20]. In order to answer the disputable question concerning the generation spectra of CLC lasers of type 1, we have studied in detail the optical characteristics of planar textures of both CLCs on the basis of either cholesterol esters or induced CLCs, in particular, the transmittance and fluorescence of their pure and dyedoped layers. We have also analyzed the generation spectra of CLC lasers with the natural (type 1) and induced (type 2) helix structures in order to reveal a relation between them and the optical characteristics of various CLCs.

\section{Experiments and Their Discussion}

The following ternary mixture of cholesterol esters was used as a type-1 CLC matrix: $40 \%$ of Tecon-20 (cholesteryl oleate), $35 \%$ of cholesteryl pellargonate, and $25 \%$ of cholesteryl chloride. The temperatureinduced change of the corresponding helical pitch was about $3 \mathrm{~nm} /{ }^{\circ} \mathrm{C}$. The CLC mixture was activated with the help of 3-dimethylaminobenzantrone and the phenolenone dye F490 (NPOPIK, Dolgoprudnyi, Russia) introduced at a concentration of $0.3 \mathrm{wt} \%$. The CLC mixture had a left-helical twist, with the SR band maximum at about $600 \mathrm{~nm}$. The birefringence in the given ternary mixture of cholesterol esters was about 0.04. The thickness of the dye-doped cholesteric layer in the oriented specimen with the planar texture was 
40-45 $\mu \mathrm{m}$. The planar texture was created following the standard technology $[5,28]$.

A mixture of Tecon-20 (37\%) and nematic ZhK-654 (63\%, NPOPIK, Dolgoprudnyi, Russia) was used as a matrix of the induced CLC. The induced CLC was activated using the F490 dye. The dye concentration was $0.2 \%$, and the thickness of the planar texture layer was $30 \mu \mathrm{m}$. The SR spectral maximum for the induced CLC was also located at about $600 \mathrm{~nm}$.

The mixtures of cholesterol esters are characterized by a high viscosity. Therefore, for their orientation, besides the application of orienting structured substrates, their relative shift in the rubbing direction is used [25]. The technology of creating a planar texture with a helix axis directed perpendicularly to the orienting surfaces included (i) the rubbing of a layer of polyimide varnish (PIV, less than $1 \mu \mathrm{m}$ in thickness) which was deposited onto a glass or quartz substrate over a transparent electrode layer (ITO) and (ii) after filling the specimen, the relative shift of the layers along the rubbing direction at a temperature close to the phase transition one. However, when fabricating the planar texture of low-viscous induced CLCs, only orientating structured substrates were applied.

The transmission spectra of planar CLC textures were studied on SF-20 and SF-10 spectrophotometers, and the fluorescence spectra on a Hitachi MPF-4 spectrometer. It is known that, in contrast to modern spectrometers with CCD matrices, when studying the fluorescence on a spectrometer with the classical excitation scheme, the specimen is arranged at an angle of $45^{\circ}$ with respect to the exciting radiation and, accordingly, the fluorescence radiation is registered at the same angle with respect to the helix axis, when studying dye-doped CLCs. We note that the position of the SR band in the CLC depends on the observation angle. Therefore, for the indicated angle value, it will be significantly shifted toward short waves and will go beyond the frequency interval of the dye fluorescence spectrum. In order to register the fluorescence radiation in the direction along the CLC helix axis, a specially designed mirror attachment has to be used. When studying the fluorescence of dye-doped CLCs, a linear polarizer with an achromatic quarterwave plate was also applied to analyze the circularly polarized radiation.

The lasing parameters were studied using a typical experimental setup. The optical pumping of the CLC laser was performed by means of the second harmonic
( $\lambda=530 \mathrm{~nm}$ ) of a Q-switched neodymium-glass laser with a pulse duration of about 20 ns. The secondharmonic radiation was focused by means of a lens with a focus length of $21 \mathrm{~cm}$ to turn in pumping beam about $0.5 \mathrm{~mm}$ in diameter and directed onto a cell with a planar-oriented dye-doped CLC. The ratio between the beam diameter and the CLC layer thickness was about 11.1. The pumping pulse energy was varied in a stepwise manner, and it was monitored with the help of a laser calorimeter. The maximum put on pumping intensity did not exceed $27 \mathrm{MW} / \mathrm{cm}^{2}$. The lasing spectra were formed in the focal plane of a spectrograph with a reciprocal dispersion of $0.6 \mathrm{~nm} / \mathrm{mm}$ and registered on a PC monitor using a video camera.

Figure 1, a demonstrates the transmission spectrum for a type-1 CLC specimen fabricated on the basis of the mixture of cholesterol esters and doped with 3-dimethylaminobenzanthrone. A minimum at about $580 \mathrm{~nm}$ was induced by the SR spectrum of the helical CLC structure, and a minimum at about $480 \mathrm{~nm}$ by the dye absorption band. The fluorescence spectrum of the dye-doped CLC underwent a significant distortion, which depends on the registration geometry and the analyzed polarization. In particular, if fluorescence was registered at an angle of about $45^{\circ}$ with respect to the helix axis, the radiation was almost completely depolarized, and the radiation spectrum did not differ from the fluorescence spectrum of the dye in an isotropic solution. In the case of diffracting circular polarization and provided the registration in the CLC helix axis direction, the fluorescence contour became distorted, as is shown in Fig. 1, $b$. One can see that there appeared a dip in the fluorescence spectrum, whose frequency interval coincides with the SR spectrum of the CLC matrix. In the case of nondiffracting right circular polarization, the fluorescence spectrum was not distorted, as this occurs in the case where the registration is performed at an angle of $45^{\circ}$ with respect to the CLC helix axis.

The fluorescence spectrum of the induced CLC on the basis of the mixture of nematics ZhK-654 $(63 \%)$ and Tecon-20 (37\%) underwent similar modifications. In this case, as is shown in Fig. 2 (curve 1), if the registration was performed at an angle of about $45^{\circ}$ with respect to the helix axis, the radiation was almost completely depolarized, and the radiation spectrum did not differ from that of the dye in the isotropic liquid. When the radiation was registered in the direction of the induced CLC helix axis 

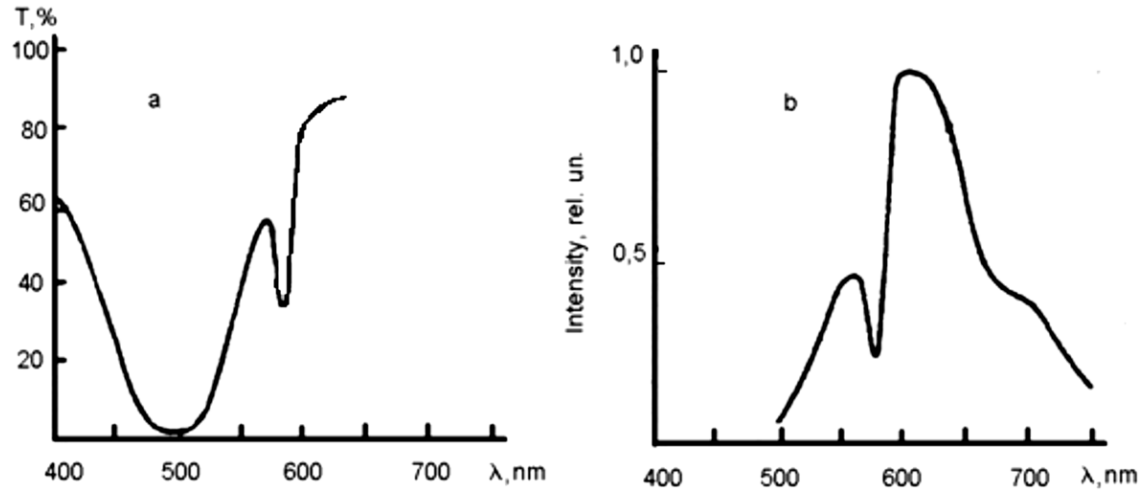

Fig. 1. The first observation of photon localization in the periodic structure of steroid CLC: the transmission spectrum of dye-doped CRC at a layer thickness of $40 \mu \mathrm{m}(a)$; the fluorescence spectrum of the same specimen in the direction along the helix axis for the diffracting circular polarization $(b)$. The CLC layer thickness is $30 \mu \mathrm{m}$

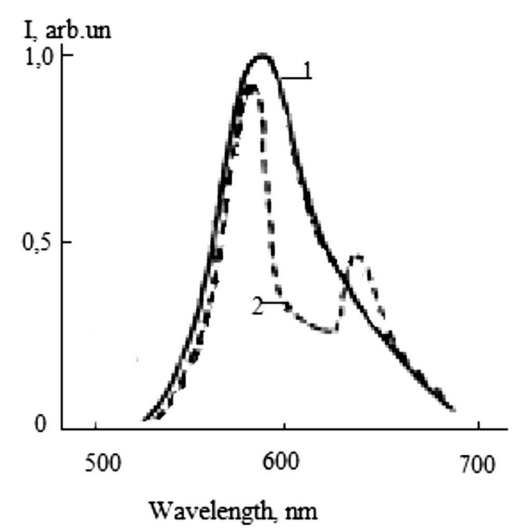

Fig. 2. Fluorescence spectra of dye-doped induced CLC (the mixture ZhK- $654+36 \%$ of Tecon-20): registration at an angle of $45^{\circ}$ with respect to the helix axis (1); registration along the helix axis for the left circular polarization (2). The CLC layer thickness is $30 \mu \mathrm{m}$

(Fig. 2, curve 2), the band polarization increased, and the polarization degree equaled 0.29 for the degree of dye ordering in this matrix $S=0.25$. As can be seen from Fig. 2, in the case of diffracting circular polarization, the contour of the fluorescence band became deformed by a dip that coincides in its frequency interval with the SR spectrum of the CLC matrix.

The analysis of the shape of the transmission spectra of steroid CLCs demonstrates a clear dependence of the SR band width on the planar texture quality. A better orientation was observed on substrates firstly covered with a layer of transparent electrodes (ITO) and, afterward, with a layer of polyimide varnish (PIV), as was done in work [28]. The quality of a planar texture affects its transmission spectra; first of all, these are the SR bandwidth and the maximum reflection intensity. For planar textures fabricated with the use of glass and quartz substrates covered with a layer of transparent electrodes and a layer of polyimide varnish, the half-width of the SR band equaled $22-24 \mathrm{~nm}$ when the indicated mixture of steroid CLCs was used. For steroid CLCs, the planar texture retained its high quality at thicknesses up to $50-55 \mu \mathrm{m}$. In the case of a high-quality planar texture, a clear mode structure was observed in the lasing spectrum. Otherwise, this structure transformed into a diffuse generation band. It should be noted that the presence of a transparent electrode (ITO) on the orienting substrate only affects the planar texture ordering, which manifests itself in the width and the diffraction efficiency of the SR band. Under the conditions of a non-selective resonator created by transparent electrodes with the reflection coefficient $R=8 \div 10 \%$, no lasing arose beyond the SR band within the whole excitation intensity interval up to the specimen destruction.

For the induced CLC, a high-quality planar texture survived at the specimen thicknesses up to $30 \mu \mathrm{m}$, with the minimum generation threshold being also registered at this thickness. As one can see from Fig. 6, $b$, the half-width of the SR band was about $59 \mathrm{~nm}$.

Hence, a comparative study of the lasing spectra was carried out using high-quality specimens of the planar texture in the dye-doped CLCs of both types. The lasing spectra were controlled by both the

ISSN 2071-0194. Ukr. J. Phys. 2020. Vol. 65, No. 4 
SR bandwidth and the non-selective scattering beyond the SR band, which did not exceed $1 \%$. As early as in the first experiments on the lasing in steroid CLCs $[4,5]$, we found that the lasing spectrum is located in the SR band close to its center. Furthermore, the temperature-induced change of the helix pitch resulted in a smooth tuning of the lasing frequency, which nevertheless remained inside the SR band of the CLC. Such a behavior is described by the model of coupled waves for the lasing in a periodic structure [23]. No other generation band, which would be characteristic of the model of photonic crystals, was observed when varying the position of the SR band within the limits of the dye fluorescence band by changing the weight proportion of the CLC components.

In order to reliably verify the correspondence of the lasing mechanism in the CLC to a definite model, we shifted the SR bands of both natural and induced CLCs into the region of the doping-dye fluorescence maximum. For both CLC types, it was the F490 dye. In Fig. 3, the transmission spectrum of natural CLC is presented by curve 1 . As one can see, the $\mathrm{SR}$ band (with the minimum at about $600 \mathrm{~nm}$ ) is located in the region of the dye fluorescence spectrum maximum (curve 2). Such an arrangement provides the maximum gain within the SR band and creates optimum conditions for the generation of two lines (bands). According to the photonic-crystal model, those lines have to be generated within the limits of $\pm 11 \mathrm{~nm}$ and located symmetrically with respect to the maximum (at about $600 \mathrm{~nm}$ and with a halfwidth of about $22 \mathrm{~nm}$ ).

However, no other generation band was registered within a wide excitation intensity interval ranging from the threshold value $I_{t h}$ to a level at which the thermally induced destruction of the specimen took place $\left(\sim 10^{3} I_{\mathrm{th}}\right)$. Instead, in a wide range of excitation intensities, there arose a band consisting of three lines in the lasing spectrum (Fig. 4). The central line of this band $(\lambda=603 \mathrm{~nm})$ coincided with $\lambda_{\mathrm{Br}}=602 \mathrm{~nm}$ of the SR band to within an experimental accuracy of $\pm 1 \mathrm{~nm}$. Thus, in this experiment, when obtaining the maximum gain in the CLC, the lasing frequency exactly coincided with the Bragg frequency of the periodic structure, which was predicted in the framework of the Kogelnik-Shank theory [23] in the case where the gain exceeds the level of coupling between the forward and backward waves in the periodic structure.

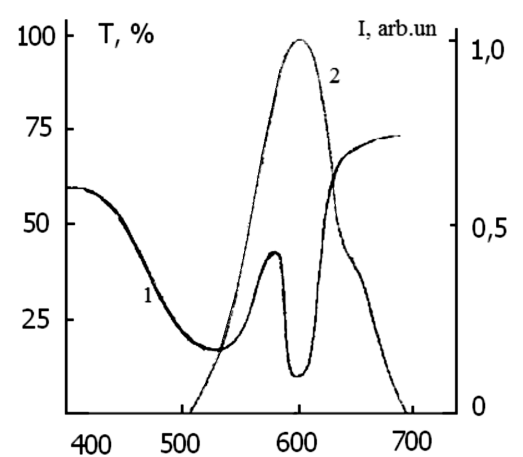

Fig. 3. Transmission spectrum of dye-doped steroid CLC (the ternary mixture of cholesterol derivatives and the dye F490) for diffracting circular polarization (1); fluorescence spectrum of the same sample for non-diffracting circular polarization (2). The layer thickness is $45 \mu \mathrm{m}$.

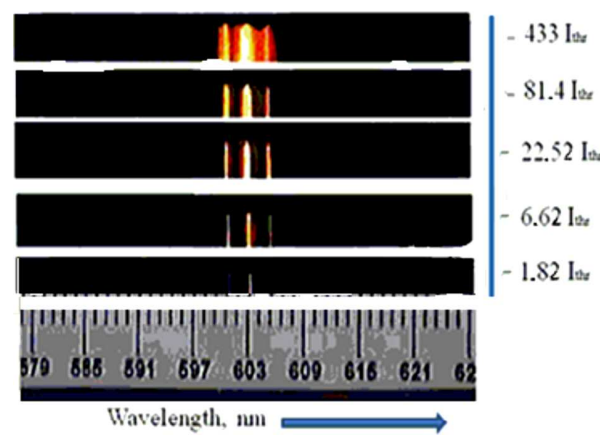

Fig. 4. Lasing spectra of the steroid CLC specimen presented in Fig. 3 for various excitation intensities. The layer thickness is $45 \mu \mathrm{m}$

As one can see from Fig. 4, the lasing spectrum of the steroid CLC consists of three lines. The central line corresponds to the Bragg wavelength, and two lateral ones are longitudinal modes with the indices $N=+1$ and $N=-1$. Note that, under the experimental conditions, if the thickness of the CLC layer equals $45 \mu \mathrm{m}$, the lasing thresholds for longitudinal modes with the indices $N=+1$ and $N=-1$ are rather low, being only by $10 \%$ higher than the corresponding value for the fundamental Bragg mode. The distance between the longitudinal modes in a CLC laser, reciprocally to other lasers based on the Fabry-Perot interferometer, is determined as $\delta \lambda \approx \lambda^{2} /(2 n L)$, where $\lambda$ is the wavelength of the fundamental mode, $n$ the average refractive index of the CLC, and $L$ the active layer thickness. At $\lambda=600 \mathrm{~nm}, n=1.53, L=45 \mu \mathrm{m}$, and $\delta \lambda=2.6 \mathrm{~nm}$, the total width of the lasing spectrum 


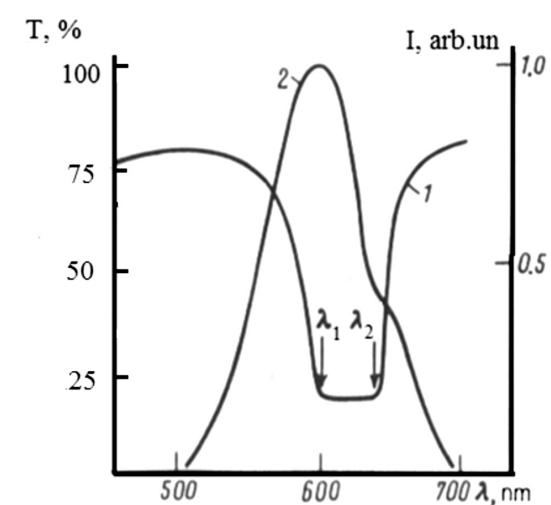

Fig. 5. Transmission spectrum of pure induced CLC (the mixture ZhK-654 $+36 \%$ of Tecon-20) for the diffracting circular polarization (1); fluorescence spectrum of the dye F490 in this mixture for the non-diffusing circular polarization (2). The layer thickness is $30 \mu \mathrm{m}$. The arrows mark the positions of the lasing lines

is about $5.2 \mathrm{~nm}$. Under such conditions, the gain magnitudes for those modes are almost identical owing to the broad band of dye fluorescence (and, accordingly, the threshold gain) (see Fig. 3). The lasing spectra depicted in Fig. 4 testify to the absence of a doublet on both the central (Bragg) line and the lateral modes, which does not confirm a hypothesis proposed in work [20] to explain the cause for the lasing at the center of the SR band in steroid CLCs.

Because of a relatively large thickness of the active layer $L=45 \mu \mathrm{m}$ in comparison with a value of 10-15 $\mu \mathrm{m}$ for induced CLCs, the following remark has to be made concerning a hypothesis about the presence of a defect in the helical structure of steroid CLCs as an origin of the lasing within the SR band limits [27]. As was established in our experiments $[4,5,13]$ and in the works of other authors [28, 29], the uniformity of helical structure in the viscous mixtures of cholesterol esters survives up to thicknesses of about $50 \mu \mathrm{m}$. As was indicated above, the quality of the planar texture in our experiments was monitored on the basis of the width of the SR band and the scattering light magnitude beyond its limits. Experiments on laser generation were performed making use of high-quality planar textures of planeparallel CLC layers. They drastically differed from low-quality textures: the width of the SR band for the latter was from 1.3 to 1.5 times larger, and the corresponding lasing thresholds grew to an unreachable level.
In our work [30], a defect in the helical structure of a steroid CLC was created by rotating the orienting substrates. In this case, under certain conditions, a dip could arise within the SR band in the selective transmission spectrum, and the lasing was performed at the frequencies of this dip. In such a way, a defect in the helical structure of a steroid CLC can be diagnosed by both the anomalous broadening of the SR band and the presence of a dip at the SR frequencies in the transmission spectrum. No features of those kinds were observed in the planar textures of steroid CLCs used by us for the lasing, so that the hypothesis proposed in work [27] has not been confirmed.

In Fig. 5, the SR band of an induced CLC without dye-doping (curve 1) and the fluorescence spectrum of the dye F490 in this CLC (curve 2) are depicted. As one can see, the fluorescence maximum is shifted by $4 \mathrm{~nm}$ toward long waves in comparison with the steroid CLC and is equal to $599 \mathrm{~nm}$. Under such an arrangement of the SR spectrum, the fluorescence maximum coincides with the left (short-wave) edge of the SR spectrum. The Bragg wavelength determined at the half-width of the SR band equals $608 \mathrm{~nm}$, and its half-width equals $59 \mathrm{~nm}$. Under those conditions and using a specimen of the induced CLC $30 \mu \mathrm{m}$ in thickness, we obtained the two-band lasing with the central wavelengths $\lambda_{1}=592 \mathrm{~nm}$ and $\lambda_{2}=638 \mathrm{~nm}$, which correspond to the SR band edges in the induced CLC.

The shift of the rather narrow SR band of the induced CLC into the region of the doping-dye fluorescence maximum made it possible to realize the two-band lasing at the band gap edges. If a more efficient, in comparison with the cholesterol derivative, twisting dopant is applied, the SR bandwidth of the induced CLC increases and becomes comparable with the dye fluorescence bandwidth. In this case, only one generation band, namely, with a lower excitation threshold, remains at one of the SR band edges, but beyond its wide plateau. As can be seen from Fig. 5, the lasing in the induced CLC may correspond to the model of photonic crystals [26, 27], because it demonstrates a prohibition of the radiation emission extension within the plateau in the SR band for the given class of materials with a spatial modulation of the refractive index.

The described differences in the arrangement of lasing spectra with respect to the SR band in steroid and induced CLCs were detected for planar texture

ISSN 2071-0194. Ukr. J. Phys. 2020. Vol. 65, No. 4 


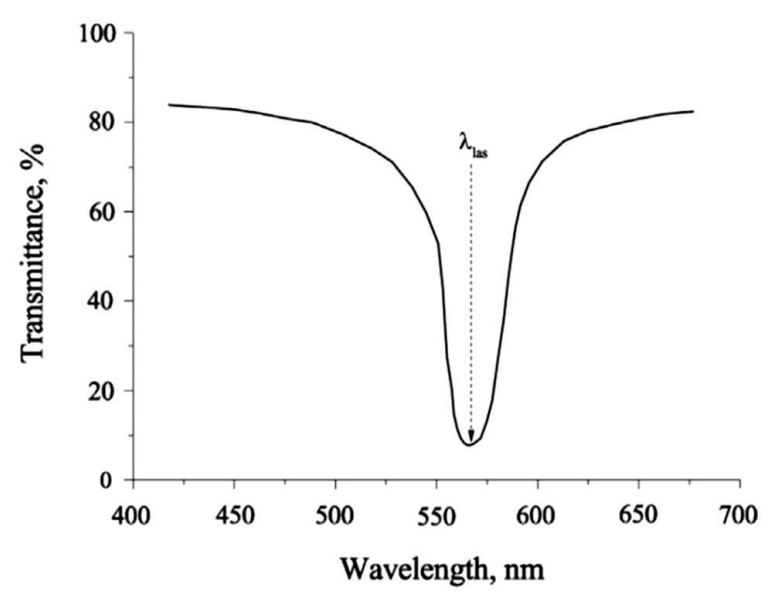

$a$

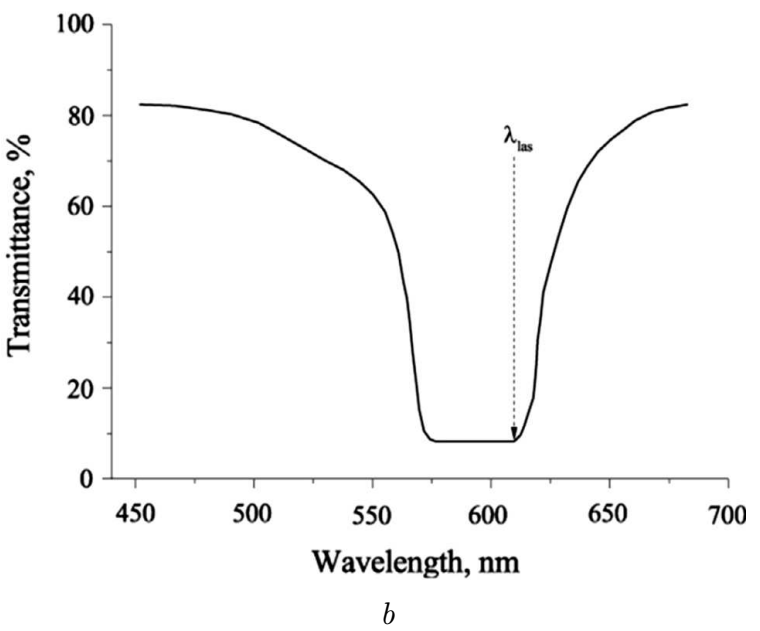

$b$

Fig. 6. Arrows mark the positions of the lasing lines with respect to the SR band for natural $(a)$ and induced $(b)$ CLCs at the thicknesses of planar texture layers that are optimal in the lasing threshold. Diffracting circular polarization. The layer thicknesses are $45 \mu \mathrm{m}(a)$ and $30 \mu \mathrm{m}(b)$

layers with optimal thicknesses, when the minimum lasing thresholds are achieved. This behavior correlates with the selective transmission spectra of pure CLC layers under indicated conditions (Fig. 6). The main difference between the transmission spectra of natural (Fig. 6, a) and induced CLCs is the absence of a plateau in the SR maximum. The analysis of the thickness dependence of SR spectra for CLCs of both types showed that the plateau appeared in the transmission spectra of induced CLCs already at layers' thicknesses of $5-10 \mu \mathrm{m}$. At the same time, in natural CLCs, an acute maximum in the transmission spectra is observed even at layer thicknesses larger than $100 \mu \mathrm{m}$, when the helix axis orientation becomes violated. Similar data on the shape of transmission spectra of natural CLCs were also obtained in works [28, 29].

The absence of a plateau in the SR band of natural CLCs testifies that, in contrast to induced CLCs, there is no total reflection within the half-width of the SR band in this case. This conclusion is also confirmed by the lasing within the SR band.

\section{Conclusions}

1. Fluorescence quenching at the frequencies of the selective reflection in CLCs testifies to the localization of photons with the corresponding frequencies within the reflection spectrum interval or within the band gap in the case of photonic crystal.
2. The coincidence of the lasing band and the center of the SR band in a CLC laser at the maximum laser gain means that the laser operates according to the distributed feedback model. This is also evidenced by a stronger selectivity of the periodic helical structure, which was predicted in work [25] and which was observed in our experiments on the lasing in natural CLCs.

3. The absence of lasing lines at the SR band edges in natural steroid CLCs and the absence of a doublet in the SR band spectrum in a wide excitation intensity interval reject the hypothesis of the lasing according to the photonic-crystal model.

4. The difference between the lasing spectra in natural steroid and induced CLCs correlates with the difference between their transmission spectra. For steroid CLCs, provided that their orientation is preserved, no total reflection within the SR band halfwidth can be reached for all practically possible layer thicknesses. In induced CLCs, the SR spectrum with a characteristic plateau is formed, which characterizes the prohibition for the radiation with the corresponding frequencies to propagate, if the modulation depth of the refractive index and the layer thickness reach definite values.

The publication contains the results of researches carried out in the framework of the Special Program of the Presidium of the NAS of Ukraine (project VTs-188). 
1. V.P. Bykov. Spontaneous emission in a periodic structure. Zh. Èksp. Teor. Fiz. 62, 505 (1972) (in Russian).

2. R. Dreher, H. Schomburg. Prolongation of fluorescence decay time by structural changes of the environment of the emitting molecule. Chem. Phys. Lett. 25, 527 (1974).

3. E. Yablonovitch. Inhibited spontaneous emission in solid state physics and electronics. Phys. Rev. Lett. 58, 2059 (1987)

4. I.P. Ilchishin, E.A. Tikhonov, V.G. Tishchenko, M.T. Shpak. Generation of a tunable radiation by impurity cholesteric liquid crystals. JETP Lett. 32, 27 (1980).

5. I.P. Ilchishin, A.G. Kleopov, E.A. Tikhonov, M.T. Shpak. Stimulated tunable radiation in an impurity cholesteric liquid crystal. Bull. Acad. Sci. USSR Phys. Ser. 45, 13 (1981).

6. R.G. Hulet, E.S. Hilfer, D. Kleppner. Inhibited spontaneous emission by a Rydberg atom. Phys. Rev. Lett. 55, 2137 (1985).

7. A.F. Munoz, P. Palffy-Muhoray, B. Taheri. Ultraviolet lasing in cholesteric liquid crystals. Opt. Lett. 26, 804 (2001).

8. J. Schmidtke, W. Stille, H. Finkelmann, S.T. Kim. Laser emission in a dye doped cholesteric polymer network. Adv. Mater. 14, 746 (2002).

9. L.-J. Chen, J.-D. Lina, C.-R. Lee. An optically stable and tunable quantum dot nanocrystal-embedded cholesteric liquid crystal composite laser. J. Mater. Chem. C 2, 4388 (2014)

10. A. Chanishvili, G. Chilaya, G. Petriashvili, R. Barberi, R. Bartolino, G. Cipparrone, A. Mazzulla, R. Gimenez, L. Oriol, M. Pinol. Widely tunable ultraviolet-visible liquid crystal laser. Appl. Phys. Lett. 86, 051107 (2005).

11. I. Ilchishin, L. Lysetskiy, T. Mykytiuk, M. Serbina, G. Chilaya. UV-radiation cotrolled tunable cholesteric dye laser based on an azoxy nematic matrix. Mol. Cryst. Liq. Cryst. 542, 221 (2011).

12. M.-Y. Jeong, K. Kwak. Active thermal fine laser tuning in a broad spectral range and optical properties of cholesteric liquid crystal. Appl. Opt. 65, 9378 (2016).

13. I.P. Ilchishin. Optimizing energy output and angular divergence of a DFB laser with cholesteric liquid crystal. Bull. Russ. Acad. Sci. Phys. 60, 494 (1996)

14. I. Ilchishin. Spectral and lasing characteristics of the dyedoped cholesteric liquid crystals as the materials for laser projection screens. Proc. SPIE 5507, 368 (2004).

15. K. Dolgaleva, S.K.H. Wei, S.G. Lukishova, Sh.H. Chen, K. Schwertz, R.W. Boyd. Enhanced laser performance of cholesteric liquid crystals doped with oligofluorene dye. J. Opt. Soc. Am. B 25, 1496 (2008).

16. I.P. Ilchishin, E.A. Tikhonov, M.T. Shpak. Damage to the planar texture of absorbing cholesteric liquid crystals by pulsed laser radiation. Sov. J. Quant. Electron. 17, 1567 (1987).
17. V.A. Belyakov, S.V. Semenov. Optical defect modes in chiral liquid crystals. JETP 112, 694 (2011).

18. V.I. Kopp, Z.Q. Zang, A.Z. Genack. Lasing in chiral photonics structures. Progr. Quant. Electron. 27, 369 (2003).

19. G.E. Nevskaya, S.P. Palto, M.G. Tomilin. Microlasers on liquid crystals.Sov. J. Opt. Techn. 77, 13 (2010).

20. R. Bartolino, L.M. Blinov. Liquid crystal microlasers (introductory notes). In: Liquid Crystal Microlasers. Edited by L.M. Blinov, R.Bartolino (Transworld Research Network, 2010), p. 1.

21. I.P. Ilchishin, E.A. Tikhonov. Dye-doped cholesteric lasers: Distributed feedback and photonic band gap lasing models. Progr. Quant. Electron. 41, 1 (2015).

22. E.A. Tikhonov, I.P. Ilchishin. Resonance nonlinear optical properties of dye- doped liquid crystals under pulse excitation: Insight into early experiments. J. Mol. Liq. 267, 73 (2018).

23. H. Kogelnik, S.V. Shank. Coupled-wave theory of distributed feedback lasers. J. Appl. Phys. 43, 2327 (1972).

24. N.V. Kukhtarev. Cholesteric liquid crystal laser with distributed feedback. Sov. J. Quant. Electron. 8, 774 (1978).

25. H.P. Preiswerk, M. Lubanski, S. Gnepf , F.K. Kneubuhl. Group theory and realization of a helical distributed feedback laser. IEEE J. Quant. Electron. QE-19, 1452 (1983).

26. J.P. Dowling, M. Scalora, M.J. Bloemer, C.M. Bowden. The photonic band edge laser: A new approach to gain enhancement. J. Appl. Phys. 75, 1896 (1994).

27. V.I. Kopp, B. Fan, H.K.M. Vithana, A.Z. Genak. Low-threshold lasing at the edge of a photonic stop band in cholesteric liquid crystals. Opt. Lett. 23, 1707 (1998).

28. Yu.V. Denisov, V.A. Kizel, E.P. Sukhenko. Investigation of ordering of the mesophase of cholesteric liquid crystals on basis of their optical parameters. Zh. Èksp. Teor. Fiz. 71, 679 (1976) (in Russian).

29. V.A. Kizel, S. I. Kudashev. Ordering mechanism in cholesteric liquid crystals. Zh. Ekksp. Teor. Fiz. 72, 2180 (1977) (in Russian).

30. I.P. Ilchyshyn, E.A. Tikhonov, T.V. Mykytiuk. Spectralbeam features of radiation emitted by a cholesteric liquid crystal laser. Ukr. J. Phys. 63, 339 (2018).

Received 21.12.19.

Translated from Ukrainian by O.I. Voitenko

І.П. Ілъчищин, Є.О. Тихонов

ЯК ЛАЗЕРНА ФІЗИКА ПРИВЕЛА ОПТИКУ В СВІТ ФОТОННИХ КРИСТАЛІВ?

$\mathrm{P}$ е $з$ ю м е

Представлено скорочений огляд авторських досліджень, $з$ наголосом на локалізацію фотонів у спіральній структурі

ISSN 2071-0194. Ukr. J. Phys. 2020. Vol. 65, No. 4 
хірального рідкого кристала (XPK), що була вперше експериментально зареєстрована авторами. Аналіз спектральних і генераційних характеристик лазерів з розподіленим зворотним зв'язком (Р33) на основі природних XРК (тип 1) і лазерів на основі хіральних нематиків (тип 2), привів до висновку: модель фотонного кристала, яка придатна для опису механізму генерації ХРК лазерів типу 2, непридатна для ХРК лазера типу 1. Про це свідчить відсутність смуг генерації на протилежних краях смуги селективного відбивання (CB), а натомість лінія генерації розміщена по іiі центру. В даному контексті показано, що при суміщенні смуги СВ ХРК з максимумом смуги флуоресценції лазерно- го барвника, лінія генерації співпадає з центром смуги СВ з похибкою ( \pm 1 нм). При товщинах шарів в XPK лазерах обох типів, при яких зберігається якісна планарна текстура (до 50 мкм) і досягаються низькі пороги генерації, спостерігається суттєва відмінність їх оптичних характеристик. A саме - спектр CB XPK для лазера типу 1 описується наближено профілем Лоренца, тоді як контур СВ ХРК лазера типу 2 має профіль, характерний для пропускання багатошарових діелектричних дзеркал. Відповідно причини відмінностей в оптичних і лазерних характеристиках для ХPK лазерів обох типів розглянуті з використанням моделей генерації - Р33 і фотонних кристалів. 